\title{
Clare Gerada: Shame and perfectionism among doctors
}

\author{
Clare Gerada GP partner
}

Hurley Group, London

I recently had the good fortune to be invited to talk alongside firemen, air ambulance crew, and other emergency personnel about how professionals risk their lives in the service of others. Doctors, in contrast, do not (often) risk their physical wellbeing to keep us safe-indeed, the actual practice of medicine has become less dangerous. Doctors work in safer physical spaces, for shorter hours, and with better technology for more routine tasks. But, as I argued, doctors do risk their psychological lives, increasingly so-owing to shame, perfectionism, and isolation.

Shame is a powerful, primitive, and silent emotion, differing from guilt in its relation to our own personal identity. The medical profession is frequently exposed to shaming experiences, exemplified by a culture of "name, shame, and blame," for failing to meet NHS targets or for becoming unwell, especially mentally unwell. In today's medical environment the impact of errors, and the fear of committing them, may be the most pressing source of shame, while the impact of complaints leaves doctors feeling humiliated and at risk of depression or suicide.

Perfectionism, which doctors demand of themselves, becomes impossible in the real world of medical care. It's one of the most pervasive of all personality traits found in doctors, and levels of perfectionism have been increasing in society in recent decades. A large study of medical students over the past 27 years found that levels of self-oriented, socially prescribed, and professionally determined perfectionism had all increased. Given that perfectionism is a core vulnerability for mental health disorders, its increase among doctors could explain why medicine is becoming a riskier profession. ${ }^{1}$

A lack of connectedness, which is becoming endemic in the practice of medicine, adds to the risk factor among doctors. The structures in medicine where doctors can come together to train, work, play, and reflect have been reduced, removed completely, or moved to the sterile virtual world, threatening our ability to build the connections we need to work and to process our struggles.

Although I've painted a largely negative picture, I believe that the tide is turning. ${ }^{2}$ We're seeing some progress in decreasing isolation in medicine. Money has been provided to recreate lost rest spaces ("doctors' messes") in every hospital. ${ }^{3}$ The NHS long term plan $^{4}$ acknowledges the importance of all people who work in the service, and, for the first time, we have an NHS people's lead. ${ }^{5}$

But there's some way to go. If we're to make medicine a less risky profession we must support all staff in how to deal with significant events. We must bring in a no-blame, learning, fair culture. We must tackle perfectionism and have a realistic discussion with our patients and the public about the power of medicine, as well as teaching our doctors that perfectionists don't necessarily deliver better care.

Competing interests: See www.bmj.com/about-bmj/freelance-contributors. Provenance and peer review: Commissioned; not externally peer reviewed.

1 Curran T, Hill AP. Perfectionism is increasing over time: A meta-analysis of birth cohort differences from 1989 to 2016. Psychol Bull 2019;145:410-29.

10.1037/bul0000138 29283599

2 Gerada C. Clare Gerada: Doctors' mental health and stigma-the tide is turning. BMJ 2019;366:14583. 10.1136/bmj.14583 31311794

3 Rimmer A. Government commits £10m to doctors' rest facilities. BMJ 2019;365:12233. 10.1136/bmj.l2233 31097484

4 NHS England. NHS long term plan. Jan 2019. https://www.longtermplan.nhs.uk/.

5 NHS England. New chief people officer to help build the NHS workforce of the future. 1 Mar 2019. https://www.england.nhs.uk/2019/03/new-chief-people-officer/.

Published by the BMJ Publishing Group Limited. For permission to use (where not already granted under a licence) please go to http://group.bmj.com/group/rights-licensing/ permissions 